\title{
The Cultural Heritage of Family Ranches
}

\author{
By Kimberly D. Kirner
}

\section{On the Ground}

- Historic family ranching is a uniquely American cultural heritage that should be considered a cultural resource when managing rangeland.

- Public land agencies need to consider the effects of land management decisions on the cultural continuity of historic ranching families and communities.

- Ranching communities maintain and transmit cultural heritage, including folk stories and local ecological knowledge, through their interactions with historic working landscapes.

- Experiential learning forges emotional ties to the land and community necessary for cultural continuity.

- Local ecological knowledge is useful for adaptive comanagement, monitoring, and conservation.

- Continuity of local ecological knowledge is a significant factor in the resilience of ranching culture, rural pastoral economies, and working landscapes.

Keywords: public land management, cultural heritage, local ecological knowledge, comanagement, cultural continuity, resilience, cultural resource.

Rangelands 37(2):85-89

doi: 10.1016/j.rala.2015.01.007

(C) 2015 The Society for Range Management

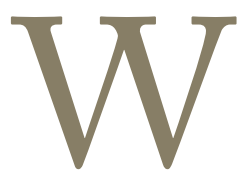

hen federal and state agencies make decisions about historically grazed allotments, ranching should be considered a cultural resource and not just an economic activity. Family ranching is an American subculture with a unique cultural heritage, and it is increasingly threatened. ${ }^{1}$ Only $2 \%$ of US citizens belong to a farming or ranching family, yet $97 \%$ of US farms are operated by families. In the face of the expansion of cities and the movement of most Americans away from an agricultural life, family ranches maintain a distinctive way of relating to the land, preserving historic sites, and continuing traditions that pass on local ecological knowledge. Rather than considering family ranches as stakeholders with only an economic interest, land management agencies should recognize the considerable cultural resources that are embedded in contemporary family ranches. Decisions that affect family ranches should include assessment of the potential impact to the continuity of their cultural heritage and local ecological knowledge.

\section{The Importance of Cultural Heritage}

What is cultural heritage? Cultural heritage are traditions, knowledge, places, and artifacts that people inherit from past generations. Cultural heritage can be tangible (such as tack, cow camps, and trails), intangible (such as cowboy poetry, stories, and local ecological knowledge), or natural (places). In this article, I explore the cultural heritage of family cattle ranchers using the mountain meadows of the Eastern Sierra, California as a case study. I have conducted ethnographic research with these ranchers in 6 different years out of the past 12. Each field session was 1 to 9 months in duration. Riding alongside ranchers throughout the Owens Valley and surrounding high Sierra meadows, I learned-through experiencing it for myself - the way that people feel about places, the stories that connected them to their past, and the knowledge that is passed on directly through engaging working landscapes.

Why should we care about cultural heritage? Why does it matter for conservation and sustainable food systems? Cultural heritage is part of an integrated system that ensures that knowledge is passed on from one generation to the next. It generates a sense of identity and motivates younger generations to learn the lifeways of their parents and grandparents. In the case of family ranchers, cultural heritage is an integral part of the continuity of local ecological knowledge. Local knowledge is complementary to formal scientific approaches to management. The two ways of knowing are similar in basing their management of resources on systematic observations of nature and detailed empirical information, with an emphasis on predicting what might happen, and helping a manager decide what to do. Local ecological knowledge provides a useful contrast to scientific studies, however, in that it contains deep and rich data on a single locale over long periods of time in ways that science rarely can provide. Additionally, it weaves this knowledge into folklore 
(songs, stories, poems) and the total cultural experience of the community. Although the cultural aspects of resource management often have been marginalized by science, increasing evidence mounts that they are important for conserving biodiversity and generating community resilience in the face of change. ${ }^{2}$

\section{Cultural Heritage in the Eastern Sierra}

Ranching is an economic lifeway and associated culture in the United States that arose from the confluence of a number of Old World pastoral traditions: Iberia, Africa, and Great Britain. The form that ranching took, and how it affected cultural heritage, varied based on the local environment. ${ }^{3}$ In the Eastern Sierra, local culture was affected by the expansion of the Hispanic vaquero tradition and adapted to meet the environment of the Great Basin. Euro-Americans entered the Eastern Sierra in the 1860s, bringing herds of cattle, horses, and sheep with them. As was the case in much of the American West, settlers set up homesteads alongside rivers and streams, using the uplands and mountain meadows for grazing livestock. The region was also strongly influenced by

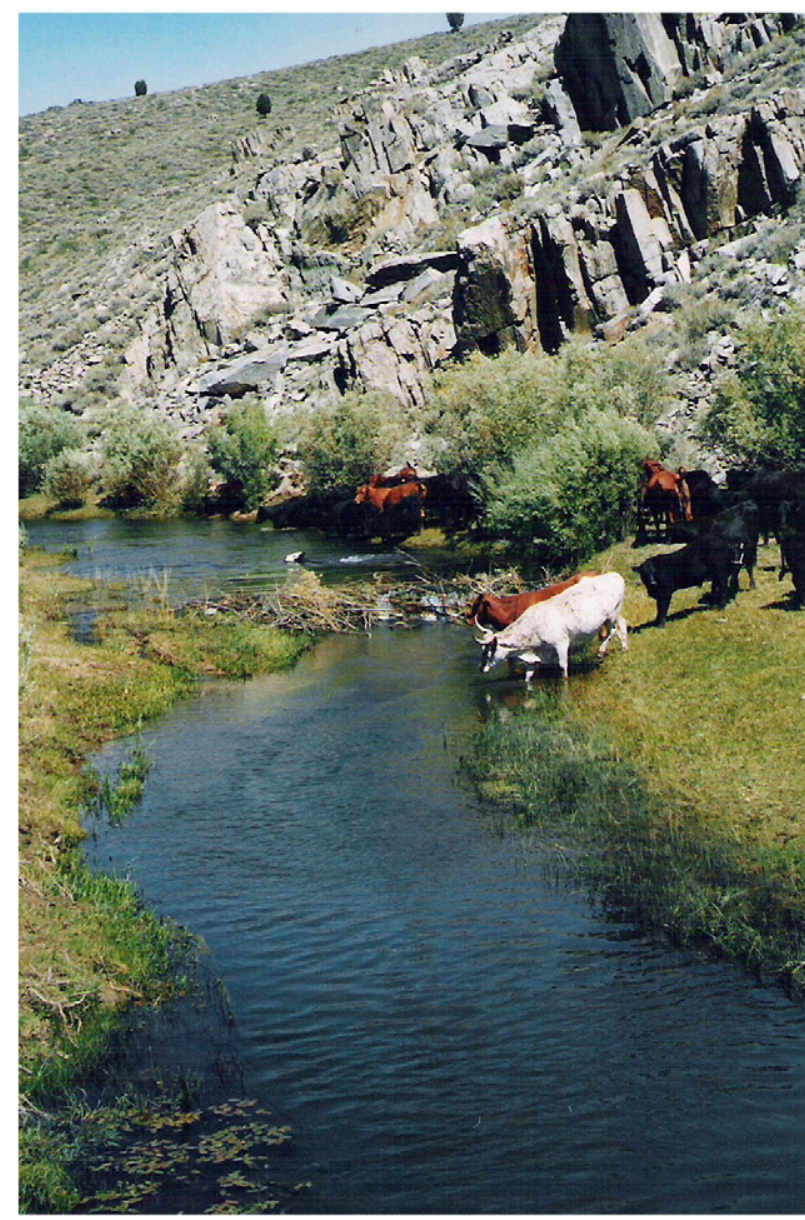

Photo 1. Cattle cross the Kern River. Ranching families' heritage includes intimate knowledge of the Kern River and how various natural events such as floods and beaver dams have changed its course over generations of time. Photo by author.
Basque pastoralists, who immigrated first to the Central Valley of California and entered the Eastern Sierra through high-altitude sheepherding, eventually settling into cattle ranching in the Owens Valley in the 1900s. Family ranching is not a new cultural lifeway, but rather one with deep historic roots to Europe, reinvented to meet local environmental and economic conditions. It represents the cultural legacy of Old World pastoralism as it was adapted to the capitalist agricultural system of the United States, federal and state land management policy, and local environments.

It has been observed, mostly in research with indigenous peoples, that local ecological knowledge is embedded in a holistic cultural system that includes folklore (e.g., stories about places) and a working relationship with the land. Ranching families, too, maintain and transmit intangible cultural heritage through their interactions with historic working landscapes. Ranching culture is intimately entwined with ecological management and family enterprise economics in complex ways. ${ }^{4}$ In the Eastern Sierra, for example, the use of high mountain meadows provides pasture for only a small percentage of most ranching families' herds. If only considered to be an economic activity, it would be easy to see using these public lands meadows as unjustified. However, they are significant for the maintenance of cultural heritage and local ecological knowledge. Scattered throughout the high country are historic sites related to settlement history, such as sheepherder cabins and corrals. Ranching families have been continually using some of the cow camps in the high country since the late 1800s. Some of these sites have inscriptions on the walls of cabins that detail family and employment history of historic ranches. Traditionally used trails sometimes feature dendroglyphs on the aspen trees, a form of communication started by Basque sheepherders and maintained through to the present day, that chart relationships of people to the land for generations. Such sites, although economically less significant than Owens Valley irrigated pastures, are an integral part of a historic working landscape that was based on verticality - the use of natural resources at various altitudes to optimize livestock production in a variable environment.

The entire system is based on the use of many different places, and deep knowledge of each of them, to adapt to uncertainties. Dry years, wet years, years with forest fires or grasshopper infestations - all are managed differently through complex, detailed, and localized on-the-ground knowledge of a variety of places. This knowledge is passed down from generation to generation through parents and children working on the land together and through telling stories about places. In my experience, these stories were usually told when triggered by specific places. Storytelling was not something that happens anywhere; stories are told near places featured in them. In this way, natural heritage (the mountain meadows), tangible heritage (cow camps, carved aspen trees, trails), and intangible heritage (stories, knowledge) are interwoven, each reinforcing the others. Taking away grazing allotments that are seemingly economically less significant still may have considerable disruption to this heritage. This is particularly a threat to the continuity of local ecological knowledge of the full range of historically grazed places and how the multisited system works 
as a whole through the fluctuations of an uncertain environment. Furthermore, high country cow camps are often a place where older youth and young adults in ranching families spend their summers, learning valuable knowledge and skills. This semi-independent experiential learning is a cornerstone in the intergenerational maintenance of ranching cultural heritage.

\section{Experiential Learning Is Essential}

Experiential learning for family ranch children is not only important for passing local ecological knowledge from one generation to another, but also for passing on cultural values associated with ranching culture. ${ }^{5}$ Historically, the emotional and aesthetic attachment to the land was as important as livestock production for ranchers. ${ }^{6}$ This trend continues into the present day: Cultural ecosystem services, quality of life, and being near natural beauty are prime motivators for ranching families. ${ }^{7}$ Experiential learning of diverse places on the range forges emotional ties to the land and the ranching

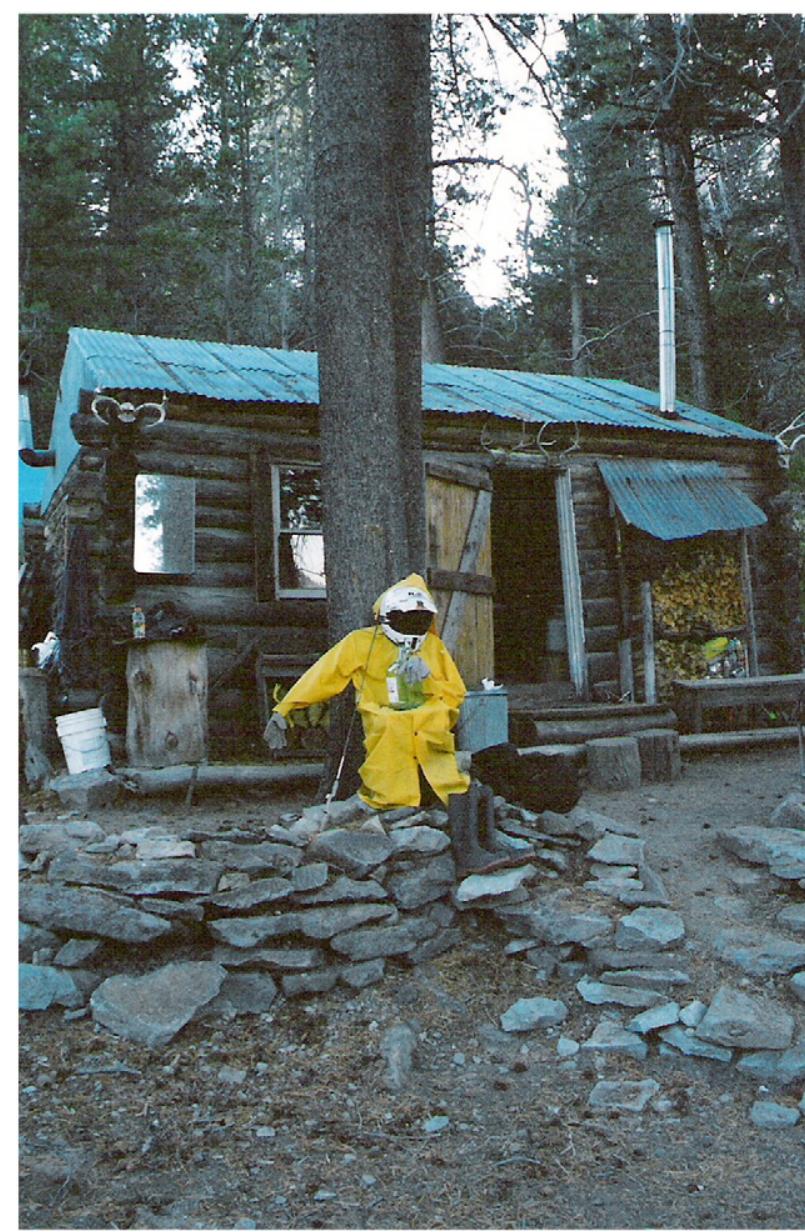

Photo 2. The cookhouse at this cow camp has been in use since the 1930s. A modern scarecrow deters bears. Ranching families maintain working landscapes that include traditionally used pastures and trails, as well as historic cabins and artifacts. Places like these are linked to stories that communicate social and environmental information from the past and the present. Photo by author. community necessary for cultural continuity. It provides the motivation for younger generations to value the culture and lifeway of ranching enough to accept opportunity costs that would bring more financial security and leisure time.

The holistic process of passing cultural heritage on to younger generations ensures the continuity of the family ranch cycle, in which leadership and management responsibility is gradually transferred from parental and grandparental generations to children. When I began my ethnographic research in 2002, many of the ranchers' children were about the same age as I-attending college as undergraduates or recently matriculated. During the summer, they would return home from college to spend time in the mountain cow camps or help in the valley. After a long break following my last field season for my doctorate, when I returned in 2011, most of that generation had returned to the ranches full time. Ranchers were in the process of carving up their land into smaller ranches for their adult children or transferring considerable management responsibility of the entire ranch to the younger generation. Toddlers in miniature boots and cowboy hats were eager to show me "their" horses and cattle. So long as the ranching system remains intact, including its diverse places and related cultural heritage, families will be able to continue their lifeway and the broader community and culture will be sustained.

Threats to the system's integrity can come, however, if too many places are removed from the system as a whole. This is because in some geographic areas, such as the Eastern Sierra, to be successful means the system must depend on multiple types of land tenure arrangements, management agencies, and ecosystems. Although some places are infrequently productive, or even go unused much of the time, they are associated with a comprehensive local ecological knowledge system and are important for providing the flexibility necessary to adjust to a constantly changing, uncertain environment. The individual ranching families who use an allotment may change over time as the families themselves expand and contract, adjusting to family size and economic concerns. However, the entire community of family ranches is cooperative in issues of the production and maintenance of local ecological knowledge, managing the land, and providing sufficient labor. The strength and resilience of the culture of the entire community is dependent on the flexible interactions they have over time, with each other and with specific grazed places. If too many cracks enter the system through economic stress, the loss of cultural heritage that produces motivation in younger generations, or too severe constraints limiting flexible management, ranches begin to be at risk for failing. When too many ranches fail in a community, the integrity of the entire system - cultural, economic, and ecological-is at risk. In a nation that has lost family agricultural enterprises (and their knowledge) at an alarming rate, it is important to preserve those that remain, both as a way of maintaining their unique heritage and for the practical value of their local ecological knowledge.

\section{Seeing Ranching in a New Way}

Faced with a rapid decline of many family agricultural enterprises in the United States, it is my hope that cooperative efforts can begin to work toward conserving not only rangeland, 
but also the cultural heritage associated with the families who have worked on it. The problems facing the range are complex, varying considerably in time and space, and necessitating solutions that no single entity can provide. ${ }^{8}$ Effective partnerships between family ranchers and land management agencies, uniting scientific approaches to management with the deep detail of local ecological knowledge, would go a long way toward resolving these problems as well as maintaining cultural heritage significant in American history. It has been widely acknowledged in conservation and resource management studies that local ecological knowledge can complement scientific knowledge by addressing different spatial and temporal scales, as well as providing a holistic approach. Although often less precise and more qualitative, local ecological knowledge provides long-term observational data and is an inexpensive way to gather data from more sites. ${ }^{9}$ Local ecological knowledge held by ranching families could be better used as an integral part of rangeland management in order to better understand the microenvironments of historically grazed places and how to best conserve or restore them.

Decisions that impact historically grazed land are frequently made by land management agencies based on faulty ideals of a pristine pre-European contact condition, rather than taking into account the complexity of restoration and conservation. ${ }^{10}$ Removal of livestock alone is not necessary or sufficient to protect biodiversity and the land ${ }^{11}$; knowledge to accomplish these goals must be location-specific. Permanent or long-term livestock exclosure may not resolve issues in restoration, and yet almost certainly negatively affects ranching cultural heritage and disrupts intergenerational transmission of local ecological knowledge. Because of this, it is important to consider the impact of such decisions on long-term cultural continuity and to work with family ranches to achieve conservation goals.

In Europe, there is a model that approaches rangeland management through a cooperative framework that forges partnerships between public agencies and family agricultural enterprises. Rather than seeing pastoralism on open pastures (including state land and conservation areas) as a problem, the European Commission has recognized that it has diverse ecological, environmental, and cultural benefits, including reducing biodiversity decline. ${ }^{12}$ Although European pastoralists also produce livestock products for sale on a market-based system, they are viewed as a valuable source of ecological knowledge and labor in comanagement. Furthermore, the European Commission specifically recognizes that such family pastoralist activities should be protected for their cultural and natural heritage. ${ }^{13}$ Unique descendants of these traditions exist within American family ranching and the historically grazed lands of the West.

Indeed, in some areas of the United States there are cases of collaborative efforts to increase the social and ecological resiliency of Western ranching landscapes. ${ }^{14}$ What is needed is a more systematic process to use adaptive comanagement models to ensure the continuity of both rangeland and the cultural heritage of those who have worked on it, recognizing the value of family agricultural enterprises as being more than economic. ${ }^{15} \mathrm{We}$ need to see ranching in a new way - as part of the cultural heritage of our nation, maintaining valuable ecological knowledge and a

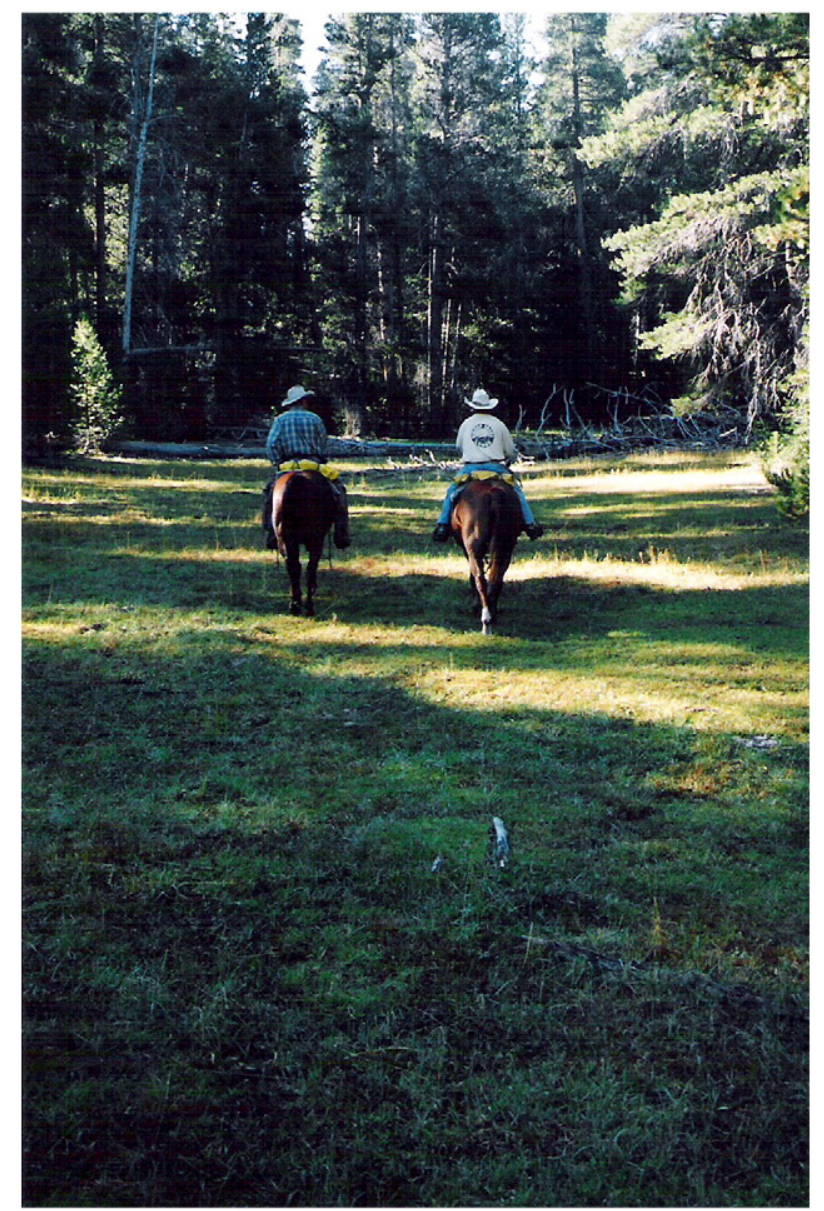

Photo 3. A rancher rides mountain meadows with his adult son, home from college. Ranchers' adolescent and young adult children often spend summers in high Sierra cattle camps, which gives them localized knowledge and hands-on experience to use alongside their degrees when they later manage ranches of their own. Place and folklore are entwined in ranching families' cultural heritage. Photo by author.

dimension of cultural diversity that has been threatened by urbanization. In so doing, we may find that we not only preserve the cultural continuity of family ranching, but also the natural heritage and historic sites to which it is tied.

\section{Acknowledgments}

The author acknowledges the ranching families of the Owens Valley and Robert Pearce (NRCS), who have given so generously of their time, stories, and knowledge to make her research possible. The author also acknowledges those institutions that funded this research: the National Science Foundation and California State University, Northridge.

\section{References}

1. Brunson MW And L Huntsinger. 2008. Synthesis paper: ranching as a conservation strategy: can old ranchers save the new west? Rangeland Ecology \& Management 61(2):137-47.

2. NaZAREA VD. 1998. Cultural memory and biodiversity. Tucson, AZ, USA: University of Arizona Press [189 pp.]. 
3. JORDAN TG. 1993. North American cattle frontiers: origins, diffusion, and differentiation. Albuquerque, NM, USA: University of New Mexico Press [439 pp.].

4. Knight RL, W Gilgert, AND E MArston, editors. 2002. Ranching west of the 100th meridian: culture, ecology, and economics. Washington, DC, USA: Island Press. [280 pp.].

5. Trimble S. 1994. A wilderness, with cows: working with landscape. In: Nabhan GP, \& Trimble S. (Eds.), The Geography of Childhood: Why Children Need Wild Places. Boston, MA, USA: Beacon Press. [216 pp.].

6. STARRS PF. 1998. Let the cowboy ride. Baltimore, MD, USA: Johns Hopkins University Press. [356 pp.].

7. Plieninger T, S Ferranto, L Huntsinger, M Kelly And C. Getz. 2012. Appreciation, use, and management of biodiversity and ecosystem services in California's working landscapes. Environmental Management 50(3):427-40.

8. BoYd CS AND TJ SveJCAR. 2009. Managing complex problems in rangeland ecosystems. Rangeland Ecology \& Management 62(6):491-9.

9. Moller H, F Berkes, POB Lyver and M Kislalioglu. 2004. Combining scientific and traditional ecological knowledge: monitoring populations for co-management. Ecology and Society 9(3):2.
10. SAYRE N. 2010. Climax and "original capacity": the science and aesthetics of ecological restoration in the southwestern United States. Ecological Restoration 28(1):23-31.

11. SAYRE N. 2005. Interacting effects of landownership, land use, and endemic species on the conservation of southwest United States rangelands. Conservation Biology 19(3):783-92.

12. Kerven C And R BehnKe. 2011. Policies and practices of pastoralism in Europe. Pastoralism 1(1):1-5.

13. ERIKSSON C. 2011. What is traditional pastoral farming? The politics of heritage and "real values" in Swedish summer farms (Fäbodbruk). Pastoralism 1(1):1-18.

14. White C. 2008. Revolution on the range: the rise of a new ranch in the American west. Washington, DC, USA: Island Press [248 pp.].

15. Olsson P, C Folke And F Berkes. 2004. comanagement for building resilience in social-ecological systems. Environmental Management 34(1):75-90.

Author is Assistant Professor of Anthropology, California State University, Northridge, Northridge, CA 91330 (kkirner@csun.edu). 